\title{
PSEUDO-GLIOMA DUE TO LARVAL CHOROIDO-RETINAL GRANULOMATOSIS*
}

\author{
BY \\ WALDRON HARRIS \\ Department of Ophthalmology, Leicester Royal Infirmary
}

IN view of the apparent rarity of the retinal larval granulomatosis described by Ashton (1960), it was considered appropriate to augment his four cases with a further example of this condition seen at this hospital.

\section{Case Report}

A little girl aged 2 years and 9 months was brought to the Ophthalmic Out-Patient Department by her mother who had noticed that the child did not appear to see well, as she was continually bumping into objects and tended to grope her way around on the floor.

The child was examined under a general anaesthetic with full mydriasis, using atropine drops. Both eyes showed a moderate degree of hypermetropic astigmatism and the fundi showed changes simulating abiotrophy of the retina, pigmentary disturbances being the predominant feature. The child was examined at intervals, and there was no apparent improvement or deterioration in vision.

One year after the first attendance, and only one month after the most recent examination, a grey reflex was seen to be appearing in the right pupillary aperture. A further examination under anaesthesia was performed and a large pseudo-gliomatous mass was found in the right eye. The fundus appearance of the left eye was unchanged from that seen one year earlier.

The right eye was enucleated and sent for pathological investigation.

Pathologist's Report.-The specimen is an eye showing detachment of the retina and fibrous reaction (Fig. 1).

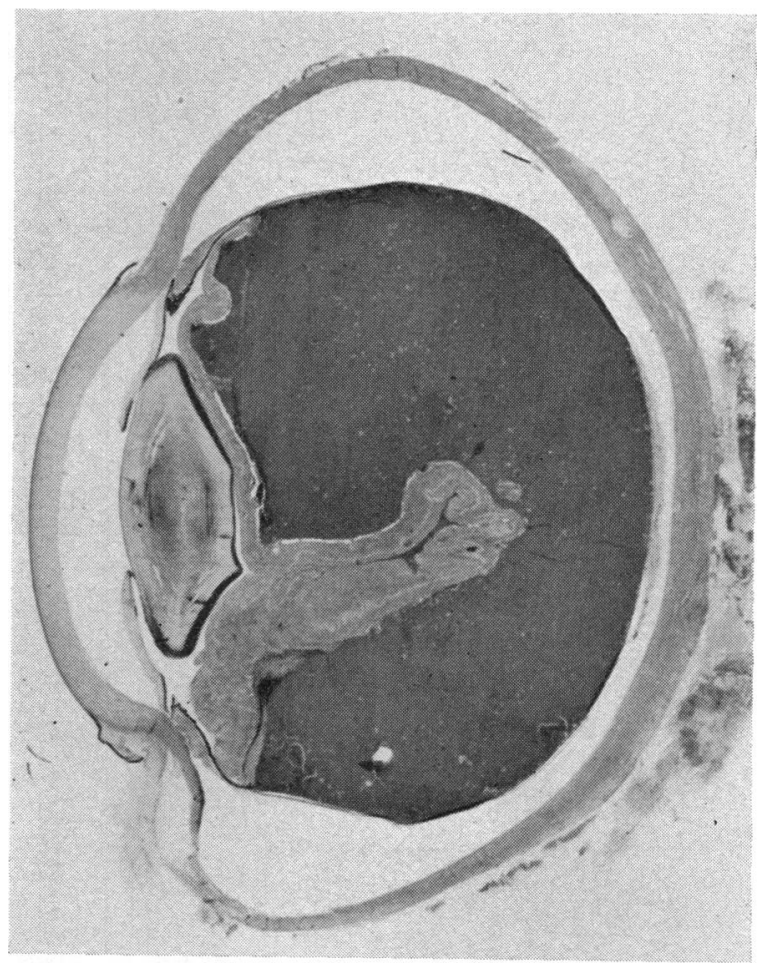

FIG. 1.-Specimen of the eye, showing detachment of the retina and fibrous tissue reaction.

This fibrous mass appears to be inflammatory in origin and the routine section showed an occasional foreign body giant cell and a fair number of eosinophils scattered throughout the fibrous tissue together with many plasma cells and lymphocytes. There is no

* Received for publication August 5, 1960. 
reaction in the ciliary body (Fig. 2). One of the serial sections prepared by Prof. Ashton in the main fibrotic mass shows an area of fibrinoid necrosis staining brightly eosinophilic with a series of giant cells around it, and projecting from the choroid is a minute granuloma with intensive eosinophilic reaction and a necrotic zone containing larval fragments (Fig. 3). Extending from it is a strip of tissue suggesting that during its

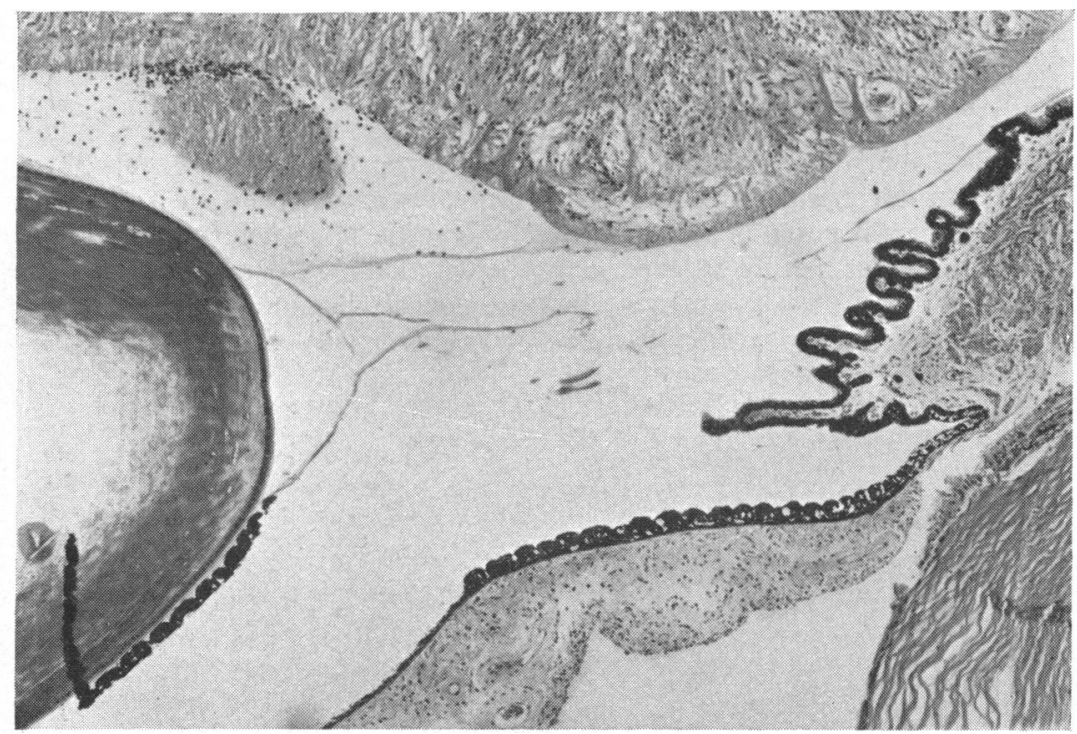

Fig. 2.-Section showing anterior part of the eye. There is no reaction in the ciliary body.

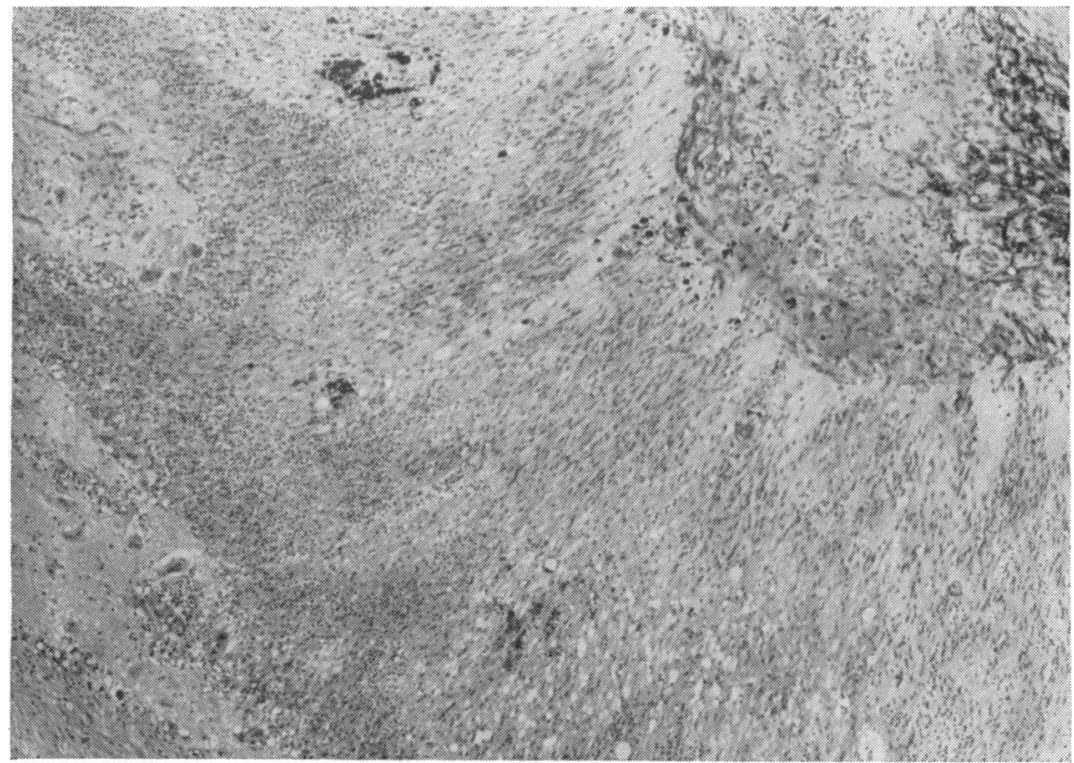

Fig. 3. - Section of part of granulomatous mass showing an area of fibrinoid necrosis staining brightly eosinophilic with a series of giant cells around it. Projecting from the choroid is a minute granuloma with intensive eosinophilic reaction and a necrotic zone containing larval fragments. 
development the main granulomatous mass, now placed behind the lens, was joined to the granuloma containing larva fragments. The fragments were too small to identify the nematode with any degree of certainty, but in width it measured 14-15 $\mu$, which corresponds to the width of the second stage larva of the Toxocara, but it could not be decided whether it was from $T$. canis or $T$. cati.

An X-ray of the skull showed no areas of calcification.

An eosinophilia of 600 per cmm. was found on April 4, 1960.

In view of the diagnosis based on the pathological report, an attempt was made to elicit further facts in the history of the case.

The child had been born on November 21, 1955, and there had been a puppy in the house until the child was 6 months old. The mother had never noticed whether the puppy had worms, and there was apparently fairly intimate contact between it and the child. There had also been a kitten in the household for a short time when the child was 3 years old, but that was after her first attendance at the Ophthalmic Department.

The child had had measles and chicken-pox, but no pneumonia, jaundice, or convulsions. She often experienced nightmares and woke up shaking.

This article was published at the suggestion of Prof. Norman Ashton and I am grateful to him for allowing me this privilege.

\section{REFERENCE}

Ashton, N. (1960). Brit. J. Ophthal., 44, 129. 